\title{
ALIGNING INDUSTRIAL ENGINEERING EDUCATION WITH INDUSTRY THROUGH ATOMIC CURRICULUM MANIPULATION
}

\author{
P.N. Chikasha ${ }^{1 *}$, K. Ramdass ${ }^{1}$, K. Mokgohloa ${ }^{1} \&$ R.W. Maladzhi ${ }^{1}$
}

\section{ARTICLE INFO}

\section{Article details}

Submitted by authors 3 Aug 2020

Accepted for publication 10 Nov 2020

Available online $\quad 14 \mathrm{Dec} 2020$

\section{Contact details}

Corresponding author

piwaichikasha@gmail.com

Author affiliations

1 Department of Mechanical and Industrial Engineering, University of South Africa, South Africa

\# The author was enrolled for a PhD (Science, Engineering \&

Technology) degree in the Department of Mechanical and Industrial Engineering, University of South Africa.

\section{ORCID® identifiers}

P.N. Chikasha

https://orcid.org/0000-0002-3897-501X

K.R. Ramdass

https: / /orcid.org/0000-0001-5480-3368

K. Mokgohloa

https://orcid.org/0000-0002-3087-1582

R.W. Maladzhi

https: //orcid.org/0000-0003-3773-8538

\section{DOI}

http://dx.doi.org/10.7166/31-4-2393
ABSTRACT

Curriculum is the primary factor that defines the competence and skill level of graduate industrial engineers as these professionals leave university and enter a dynamic industry that is affected by multiple social, economic, environmental, and political issues. If the curriculum is not adaptive, the quality of their education is compromised. This work proposes a rigid-skeleton flexible-body approach in which the architecture of the industrial engineering curriculum is rigid but has the flexibility, at a holistic level, to manipulate micro-components according to the needs of the industry. This work therefore examines the potential for atomic-type curriculum manipulation rather than molecular-type manipulation.

\section{OPSOMMING}

Kurrikulum is die primêre faktor wat die bekwaamheid en vaardigheidsvlak van gegradueerde bedryfsingenieurs definieer soos hierdie individue die universiteit verlaat en ' $n$ dinamiese industrie betreë wat beïnvloed word deur maatskaplike-, omgewings- en politiese kwessies. As die kurrikulum nie aanpasbaar is nie word die gehalte van hul opleiding benadeel. Hierdie artikel stel 'n starre-geraamte buigsame-liggaam benadering voor waarbinne die argitektuur van die bedryfsingenieurswese kurrikulum rigied is, maar met die nodige aanpasbaarheid om die nodige mikro komponente aan te pas by die industrie se behoeftes. Die artikel ondersoek dus die potensiaal vir atoomvlak kurrikulum manipulasie eerder as molekuulvlak manipulasie.

\section{INTRODUCTION AND BACKGROUND}

According to Mialkki and Paatero [1], quality of education is currently a global priority, and unless education addresses the needs of industry, economic development may be significantly compromised. Rahman, Tan and Lim [2] present the case that a dilemma has erupted in industry, such that tertiary institutions face challenges in producing graduates who are able to meet the needs of industry, while at the same time, the industry faces challenges in finding skilled graduates who are adequately equipped to meet its needs. In terms of engineering, therefore, while curriculum needs to meet international standards, it also needs to be as closely aligned as possible to local industry needs. Higher education is affected by several internal and external factors, making quality control a complex task. These factors include politics, social issues, the state of industry and commerce, national economics, institutional staff competencies, institutional funding, curriculum, and so on. Some of these factors lie within the control of the institute; and in this regard, the institute has the capability to take appropriate action to control and manage the quality of education. Curriculum is one such factor - hence the prevalence of periodic curriculum reviews and reform exercises at institutions of higher learning, typically executed at faculty level by a select committee. 
With an understanding of the importance of curriculum alignment with industry, this paper presents the research question: Can a systematic approach improve the alignment of curriculum with the skill and expertise requirements of the industry? This paper proposes an automated approach to curriculum management, and evaluates the approach against the conventional approach.

An autonomous and systematic framework is proposed to manage the industrial engineering curriculum of the Advanced Diploma in Industrial Engineering programme at the University of South Africa, in order to align it with industry needs. It is proposed that curriculum manipulation can be regarded as having two possible approaches:

1. Molecular curriculum manipulation (primary).

2. Atomic curriculum manipulation (secondary).

Primary manipulation, which is most common, is characterised by adjusting curriculum on a course-bycourse basis (molecular level) - for example, by adding or removing the topics or components that constitute a particular course. Given the integral nature of curriculum, however, this paper proposes secondary curriculum manipulation - a more meticulous and holistic approach that is characterised by atomising the entire study programme curriculum into certain key elements (curriculum elements). These elements are then manipulated at element level. The motivation for this is that curriculum courses are interrelated, with common elements across different courses. Thus, atomic curriculum manipulation is expected to improve curriculum management. Findings from this study prove that systematic atomic manipulation is more strategic and intensive in managing curriculum and in aligning curriculum with prevailing industry needs, for the benefit not only of graduates, but also of the economy.

This study relates to existing work in the field of curriculum optimisation. At an international level, the 'Conceive - Design - Implement - Operate' (CDIO) initiative plays a key role in shaping engineering education to ensure that high quality standards are maintained in engineering [3]. One of the ways in which the initiative realises its objectives is by implementing robust curriculum planning systems with outcomesbased evaluation strategies, similar in concept to the proposed curriculum management system discussed in this study [4]. The International Education Agency (IEA) also leads an international drive to digitise and decentralise the management of education by adopting an outcomes evaluation approach [5].

\section{LITERATURE REVIEW}

A higher education qualification in engineering prepares students for the industry, one that is diverse and dynamic. Kolmos, Hadgraft and Holgaard [6] reveal that engineering students graduate into a work environment that is steered by such factors as technology advancements and various social, environmental, political, and economic factors, all collectively introducing dynamics to the requirements for skills, knowledge, or expertise. If, therefore, the education system is not adaptive and dynamic, the quality of education is compromised. To adapt education, therefore, curriculum is typically periodically revised or redesigned.

\subsection{Curriculum management}

There are two levels of curriculum management. At one level, it is the process of selecting programme courses, referred to in this context as 'the student perspective' - for example, deciding which elective courses to enrol for. The second level of curriculum management is one in which a specific programme curriculum is assessed and adjusted from an institutional perspective to improve the programme's outcomes. Such is the curriculum management discussed in this paper: improving the curriculum's alignment with industry needs.

The importance of curriculum management has been discussed at length in the literature. Curriculum management is the process of evaluating study material in order to improve the learning experience of the learner [2]. Through curriculum management, higher learning institutions gain the ability to ensure the relevance of their study programmes to the industry for which students are being prepared - in fact, not only industry, but all of society. In this regard, public universities in South Africa (and in much of Africa) have embarked on prioritising curriculum redesign to achieve a more inclusive approach to education, and to decolonise knowledge [7]. Fomunyam [8], who has researched the decolonisation of the South African engineering curriculum, emphasises the need to enhance curriculum change to liberate South African engineering education. This is realised through curriculum management. 


\subsection{Characteristics of curriculum management}

The idea of curriculum management is to create a balance between the needs of the various stakeholders involved: the students, the academic institution (college), related professional bodies, and the industry. Curriculum management is a critical aspect of education [9], and higher learning institutions invest substantial resources in curriculum management each year. The most common approach to curriculum management is the conventional assessment system, characterised by periodic curriculum review exercises, executed by a sitting committee comprising selected stakeholders from the relevant faculty, which analyses the curriculum and makes recommendations. Following these exercises, recommendations are made in line with the observations that have been made. Such exercises may in some cases include current students, alumni, representatives from professional bodies, and other industrial players who are employed in the relevant sector.

Globally, curriculum management from the institutional perspective has become more inclusive and flexible, while seeking alignment with industry and society. In the global landscape, engineering education has evolved towards an integrated learning approach [10]. Perez-Foguet et al. [10] discuss curriculum management in terms of the fourth industrial revolution (Industry 4.0), arguing that engineering education needs to be transformed to meet the demands of the industry of the $21^{\text {st }}$ century by integrating all the engineering disciplines, rather than the current approach in which the curriculum is mostly disciplinedependent. Globally and regionally, curriculum management over the past decade has prioritised satisfying the need for improved problem-solving skills among graduates in industry, as well as the need to address sustainability concepts [11]. In recent decades, curriculum management has also aimed to address such key industry needs as software/technology diversity, risk management skills, and innovation and entrepreneurship [12].

The general and conventional manner in which such curriculum management has been realised is characterised by a mapping process, executed at institutional level. Alarif et al. [13] outline the process as involving a consolidation of the needs of the market (industry) and then evaluating those needs against the curriculum to refine the objectives of the programme.

\subsection{Automated curriculum management}

If curriculum management were to be automated and executed systematically, this could make the process more efficient. Some research has looked into automated curriculum management systems [14] and [15]. It is noted that highly robust systems are required in order to comprehend the complexity of the education ecosystem. However, most automated systems are designed to meet the purpose of curriculum management from the student's perspective. In fact, several higher learning institutions, especially in Europe, America, and Asia, have developed standalone systems for students to manage their individual curriculum in terms of structure and courses (elective and core). The gap is in automating curriculum management from the institutional perspective in order to improve the curriculum - in this case, to improve its alignment with industry needs. The main idea, therefore, is to automate the process of aligning curriculum with industry.

\subsection{Curriculum alignment}

An initial evaluation of the current state of curriculum alignment with industry is carried out to understand how serious the curriculum misalignment is.

Garousi et al. [16] discuss software engineering programmes in a general sense, concluding that most programmes still focus more on theoretical topics, causing a discrepancy between practical skill requirements and the skills taught in class. They emphasise that the problem is with quality, not quantity. Some improvements are proposed. The same issue is raised by Baker [17], with even more emphasis. Further study shows that this misalignment is a reality not only for engineering-related programmes: misalignment is prevalent even for artisanal professions, which are in fact expected to be as practical as the industry itself is [18]. If, for example, a student has completed carpentry training at a polytechnic college, why does the student still need post-college training to meet employers' expectations? This shows a misalignment. Misalignment is discussed [19] as a common phenomenon in higher learning, and as one of the main reasons that curriculum review is necessary to maintain the curriculum's effectiveness.

Zimmer and Keiper [19] point out that curriculum misalignment is becoming even more common owing to the growing diversity of teaching staff; and this in-turn has resulted in different interpretations of the same course objectives, ultimately causing changes to the course material without adequate consideration of the overall programme alignment. Akdur [20] illustrates how misalignment is clearly elaborated in the case 
of software practitioners: typically, graduates manage to satisfy the needs of the computing disciplines, but not so much the related electrical and electronic engineering disciplines, which are also required by the software industry. It is certain that curriculum misalignment affects the education system negatively.

This paper argues that the main cause of misalignment is the dynamic nature of the industry and the economy, which cannot be stopped. However, curriculum can be adapted to these dynamics. While it is important to align engineering education with industry needs, the level of alignment needs careful management, given the risk of becoming too rigid. It is important, therefore, to ensure that curriculum remains flexible across the value chain. Atomic manipulation allows this flexibility: global courses or modules are not trimmed or extended, but rather it is the context that is manipulated by adjusting focus areas. This allows a clear line to be maintained between industry and engineering education to avoid falling into the trap of turning the engineering degree into an industrial learnership programme.

\section{3}

\section{RESEARCH METHODOLOGY}

This paper proposes the automation of the process of curriculum management, to optimise curriculum alignment with industrial need. The idea is not to restructure the curriculum, but to enhance the existing curriculum without removing or adding any courses/modules. It is argued that it is not sufficient only to review curriculum on a periodic basis, guided by an internal staff committee; rather, a systematic approach is required that will manage curriculum continually. Figure 1 illustrates the systematic approach.

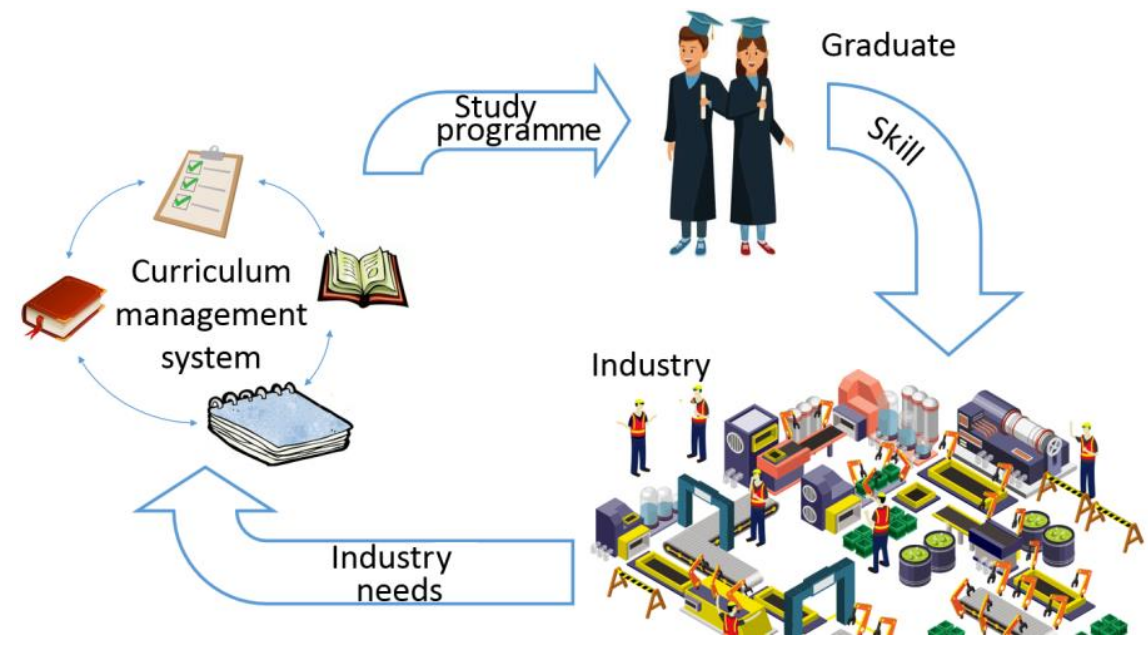

Figure 1: Systematic approach to curriculum management

The concept is to model the industry in terms of its skill requirements, and then manipulate the curriculum systematically according to the industry model, such that the graduate gains the skills required by industry.

A mixed methods research approach was adopted for this study, employing both qualitative and quantitative approaches. The reason for this was that, on the front end (data analysis), the industry needs must be presented numerically, pointing out the distribution of need across multiple curriculum elements; yet these numbers are derived from a database of qualitative on-line job advertisement posts (data collection). A mixed methods approach therefore allows the research to comprehend fully the source and destination of the research data. A deductive approach is used with interpretive analysis to examine general job advertisement information; then more specific curriculum detail is generated. The deductions made are the guided type - guided in this case by reference to relevant engineering handbooks and manuals. This is important, because this approach reduces the reliance on intuition in the process of interpreting industry survey data, relying instead on accepted standards. The objective of this study hinges on the translation of online job advertisement posts into engineering curriculum elements that can be manipulated in order to realise a improved alignment with industry needs. The following assumptions are made:

1. Job advertisements posted on the relevant digital platforms are legitimate and valid. If false job postings are listed online, for any fraudulent reason, the control data becomes contaminated, and this ultimately affects the overall accuracy of the curriculum management system. A method is 
therefore adopted to cross-reference job posts on the job advertisement platform to job post listings that are available on the official website of the respective employers.

2. The job descriptions provided with each job post are complete. Incomplete job descriptions result in a loss of data that is meant to contribute to the overall distribution of the mapped curriculum elements. It is important, therefore, to adopt an approach in which the more basic skill-set requirements are accounted for by default.

The pragmatist philosophy is adopted, on the basis that the practicality of the research outcome is of high value. If the proposed curriculum management system can align curriculum better with industry in a practical sense, then a strong case can be made for atomic curriculum manipulation, as detailed in this paper.

\subsection{Data collection}

To align curriculum with the needs of industry, a robust method to measure the needs is required. These industry needs ultimately become the input to the curriculum management system, from which recommendations are made about the adjustments that are required to align curriculum more closely with the requirements or or the state of industry. A survey method was used to collect data, through an observation approach, to consolidate primary information about the needs/requirements of the industry from job postings listed on on-line job advertisement platforms. These job posts reflected the true and practical skill/ expertise needs of the industry. Figure 2 shows the proposed structure of the management system.

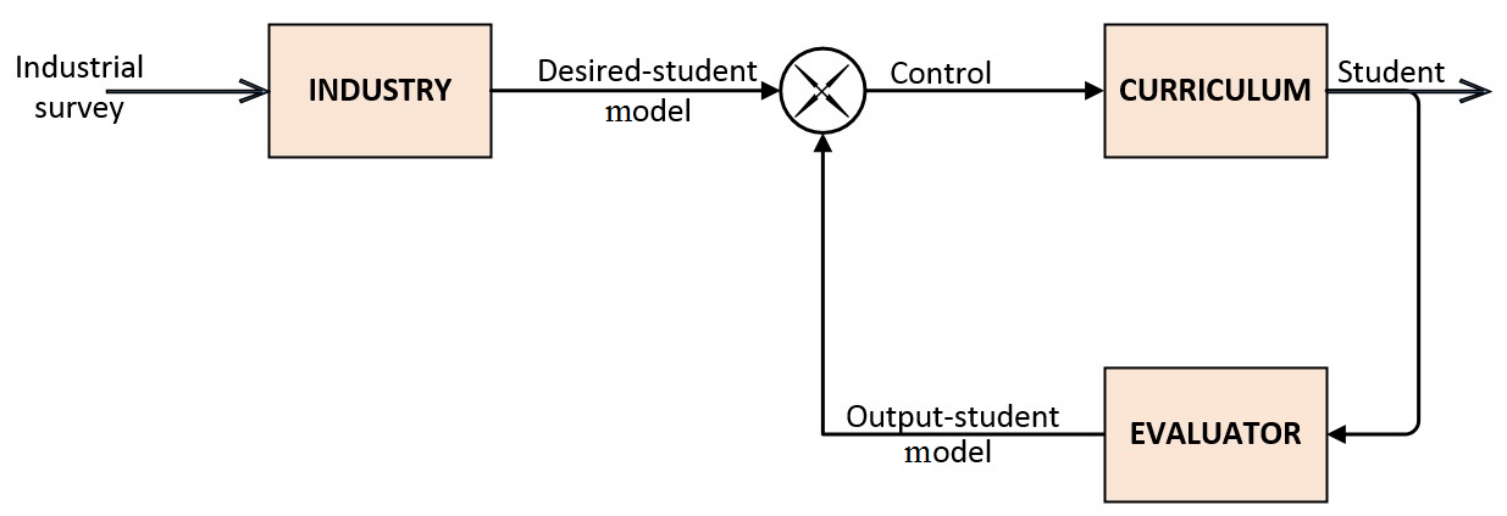

Figure 2: Structure of the curriculum management system

This structure shows that the curriculum taught during the three or four years of study is in fact determined by industry, so that graduates conceptually obtain the knowledge that is demanded and defined by industry. Through a digital survey, input data was collected from industry to create a 'desired-student model' according to the state of industry. An internal mapping process was run to map the industry needs to distinct curriculum elements, as detailed in Section 3.2.1. The delicacy of this mapping process demands a systematic and consistent approach in order to maintain accuracy. The mapping is therefore guided by reference to the following:

1. The industrial engineering handbook [21]

2. The general engineering handbook [22]

3. The discipline-specific training guide for engineering technologists in industrial engineering [23] and for engineering technicians in industrial engineering [23].

This desired-student model is then compared with an 'output-student model' that represents the graduate. In this way, it is possible to determine the relationship between the two models.

\subsection{Input data}

Primary data about the needs/requirements of the industry was collected from job advertisements listed on digital platforms using a survey. These advertisements had to be analysed in the light of the curriculum. The analysis of job advertisements to influence curricula has been investigated in work such as that of Litecky, Aken, Ahmad and Nelson [25], who proposed processing the requirements of employers into the curriculum. Through ontology, Litecky et al. mapped industrial need input data to the respective curriculum courses that directly contributed to meeting the respective industries' needs. Thus, the process of mapping 
industrial need to curriculum is understood well. In this paper, as hinted in Section 3.1, this mapping is taken a step further so that the industry needs are not mapped to curriculum courses, but rather to the curriculum elements of courses. The 'business management' need of industry, for example, is therefore mapped to the curriculum elements such as supply chain, economics, communication, human resources, resource management, sustainability, and so on.

\subsubsection{Basis for the survey}

The industry survey analysed job/project advertisements to determine the knowledge requirement of the respective job/project, as well as the corresponding curriculum elements attached to the knowledge requirement. As an illustration, a posting sought to recruit an industrial engineer to a logistics company. The position summary stated that the incumbent would be responsible for planning the utilisation of assets (personnel included) to improve the efficiency of operations and to establish work measurement programmes. The job functions were listed as follows:

1. Evaluate overall staff and individual performances.

2. Train senior staff in operational procedures.

3. Analyse and improve the workforce and asset utilisation.

4. Develop and recommend systems to improve workforce and asset utilisation and reduce waste.

5. Execute cost analysis, with the aid of engineering templates.

From that information, it was possible to establish the industrial needs presented by the case, as well as the corresponding key curriculum elements. For example, one of the skill/knowledge needs from this post was 'process evaluation', which corresponds with the following curriculum elements: data management, research skills, engineering standards, system modelling, and simulation.

Other skill/knowledge needs from this post included labour optimisation, resource optimisation, and system development. Basic curriculum elements such as languages, physics, chemistry, engineering drawing, mechanics, and mathematics were not captured because these are standard.

\subsection{Data sampling}

For this study, a purposive sample was selected for the survey. This meant that only job posts related to industrial engineering opportunities were considered. Accounting only for industrial engineering jobs avoided a contamination of the respective curriculum elements that would be processed through the management system. A total of four hundred related job posts were considered and processed for the mapping of curriculum elements. This sample size was large enough to reveal the trends in data distribution. The sample was spread across four months of job posting.

\subsection{Output data}

The input data was processed to produce output that gave an indication of which elements in the industrial engineering curriculum required attention (emphasis) so that graduates obtained sufficient skills to navigate the engineering environment. The processing of the input data to output could be regulated by control algorithms such as decision trees, lazy classifiers, artificial intelligence, and so on. This allowed the system to operate autonomously rather than manually. The output of the system showed how the various elements of the curriculum related to the state of the industry.

\subsection{Reliability and validity}

The reliability of data in this context is understood as the extent to which, if a different researcher were to conduct this study using the same methods, the same results would be produced. In order to maintain high reliability levels, a chronological approach was taken when collecting the data. The motivation was to eliminate any bias resulting from having to decide whether a particular data sample should be taken up or discarded. To validate the data, a random check approach was implemented to verify the accuracy of the curriculum mapping to the job advertisements. During the survey, data was also collected from on-line job advertisement and recruitment platforms, covering both employment and entrepreneurship (freelance) job/project opportunities, and not just employment.

\subsection{Curriculum alignment}

Now that a measurement of the needs of the industry was available (the 'desired-student model'), a measurement of the curriculum was required - that is, the 'output-student model'. The difference between the 'output-student model' and the 'desired-student model' determined how aligned the curriculum was to the industry. 
To create the 'output-student model', the graduate was assessed to determine how strongly each curriculum element had been emphasized throughout the course. This was done on the basis of assigned weights that were allocated to each curriculum element, relative to all curriculum elements. A student exit survey - a common method to evaluate curriculum from the graduate perspective - was adopted to measure the weight of each curriculum element (scaled between 1 and 10) based on how much emphasis was put on each curriculum element throughout the entire study programme. This procedure is detailed in the 'Results' section of this article.

\section{$4 \quad$ RESULTS, DISCUSSION AND INTERPRETATION OF FINDINGS}

The results from processing the collected data provided the answers to the study's research questions.

\subsection{Survey results}

The data collected from a total of four hundred on-line job/project posts was consolidated and analysed, and is presented in Figure 3, which gives the 'desired-student model' referred to in Figure 2.

\begin{tabular}{|l|r|}
\hline concept design & 1068 \\
\hline research skills & 1045 \\
\hline sys modelling\&simulation & 964 \\
\hline creative design & 937 \\
\hline engineering standards & 921 \\
\hline management practice & 909 \\
\hline optimisation theory & 846 \\
\hline data management & 836 \\
\hline computer aided design & 824 \\
\hline operational research & 807 \\
\hline planning & 777 \\
\hline financial management & 773 \\
\hline design simulation & 766 \\
\hline HR management & 759 \\
\hline sustainability & 749 \\
\hline drawing interpretation & 694 \\
\hline problem solving & 683 \\
\hline inter-faculty learning & 670 \\
\hline quality management & 645 \\
\hline
\end{tabular}

\begin{tabular}{|l|r|}
\hline management accounting & 630 \\
\hline inter-disciplinary learning & 615 \\
\hline salesmanship & 577 \\
\hline lean principles & 544 \\
\hline performance evaluation & 474 \\
\hline training and development & 435 \\
\hline workflows & 435 \\
\hline innovation & 409 \\
\hline engineering work study & 320 \\
\hline risk management & 319 \\
\hline written skills & 318 \\
\hline oral skills & 287 \\
\hline manufacturing processes & 281 \\
\hline budgeting & 250 \\
\hline office skills & 195 \\
\hline automation & 188 \\
\hline facility layout & 162 \\
\hline occupational health \& safety & 146 \\
\hline & \\
\hline
\end{tabular}

\begin{tabular}{|l|r|}
\hline scheduling & 144 \\
\hline ethics in engineering & 125 \\
\hline metrology & 123 \\
\hline reasoning & 120 \\
\hline technical evaluation & 119 \\
\hline marketing & 118 \\
\hline reverse engineering & 118 \\
\hline software development & 117 \\
\hline entrepreneurship & 98 \\
\hline accounting for engineers & 92 \\
\hline supply chain management & 77 \\
\hline negotiation & 75 \\
\hline security & 63 \\
\hline ergonomics & 63 \\
\hline renewable energy & 58 \\
\hline leadership & 56 \\
\hline economics & 55 \\
\hline legal factors & 53 \\
\hline waste management & 42 \\
\hline
\end{tabular}

Figure 3: Consolidated survey data

Figure 3 depicts the needs of the industry. The idea is to be able to manipulate the curriculum to address these needs proportionately. The top curriculum element is 'concept design'; accordingly, the explanation is that a critical demand of industrial engineering is that the incumbent can develop systems, processes, standards, and specifications for various purposes. This requires strong competencies in understanding concepts and in designing or optimising them. Also high on the list is 'research skills' because of the diverse spread of industrial engineering job duties (from the medical field to aviation and other complex fields) hence the need for advanced research skills in order to master unique job demands quickly and adequately. It is not practical to teach the student all the relevant material in class; so students need to learn how to learn independently. The 'system modelling and simulation' element also appears high on the list because industrial engineering work is heavily populated by tasks relating to the development or optimisation of systems, and this requires modelling and simulation; and so on.

\subsection{Interpreting the alignment}

The student exit survey was carried out on the basis of the industrial needs template (Figure 3). For each curriculum element, a value on a scale of 1 to 10 was given for how much the overall study programme accounted for each curriculum element (referred to in some contexts as the 'usefulness rating') from a student perspective, as seen in Figure 4, where the value of 10 represents the highest possible emphasis, while the value of 1 represents a minimal emphasis. 


\begin{tabular}{|l|}
\hline computer aided design \\
\hline design simulation \\
\hline lean principles \\
\hline problem solving \\
\hline automation \\
\hline quality management \\
\hline manufacturing processes \\
\hline facility layout \\
\hline sys modelling \& simulation \\
\hline financial management \\
\hline drawing interpretation \\
\hline engineering standards \\
\hline performance evaluation \\
\hline workflows \\
\hline scheduling \\
\hline accounting for engineers \\
\hline management practice \\
\hline optimisation theory \\
\hline creative design \\
\hline
\end{tabular}
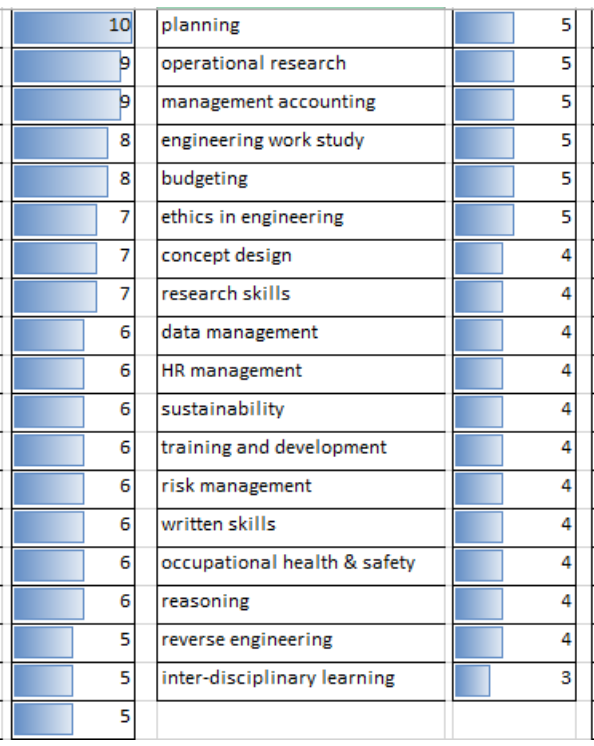

\begin{tabular}{|c|c|}
\hline inter-faculty learning & 3 \\
\hline innovation & 3 \\
\hline office skills & 3 \\
\hline marketing & 3 \\
\hline supply chain management & 3 \\
\hline renewable energy & 3 \\
\hline leadership & 3 \\
\hline salesmanship & 2 \\
\hline oral skills & 2 \\
\hline software development & 2 \\
\hline negotiation & 2 \\
\hline entrepreneurship & 2 \\
\hline ergonomics & 2 \\
\hline metrology & 1 \\
\hline security & 1 \\
\hline economics & 1 \\
\hline technical evaluation & 1 \\
\hline waste management & 1 \\
\hline legal factors & 1 \\
\hline
\end{tabular}

Figure 4: Student exit survey

Figure 4 shows, for example, that, with a value of 10 , the 'computer-aided design' element is strongly emphasised during the study programme. Compared with the needs of industry (Figure 3), the 'computeraided design' element appears high on the demand list as well; so this is strategic. However, a curriculum element such as 'concept design' raises a red flag: the demand from industry quantitatively outweighs the curriculum's emphasis on this element, thus presenting a misalignment.

In this way, the output may show positive, negative, or medium misalignment for individual curriculum elements. As seen in Figure 5, a positive mismatch means that a particular curriculum element is in greater demand by industry than is emphasised by the curriculum. In such cases, a recommendation is made to prioritise that curriculum element across all relevant courses of the programme, not just in one course. This is the idea behind atomic curriculum manipulation.

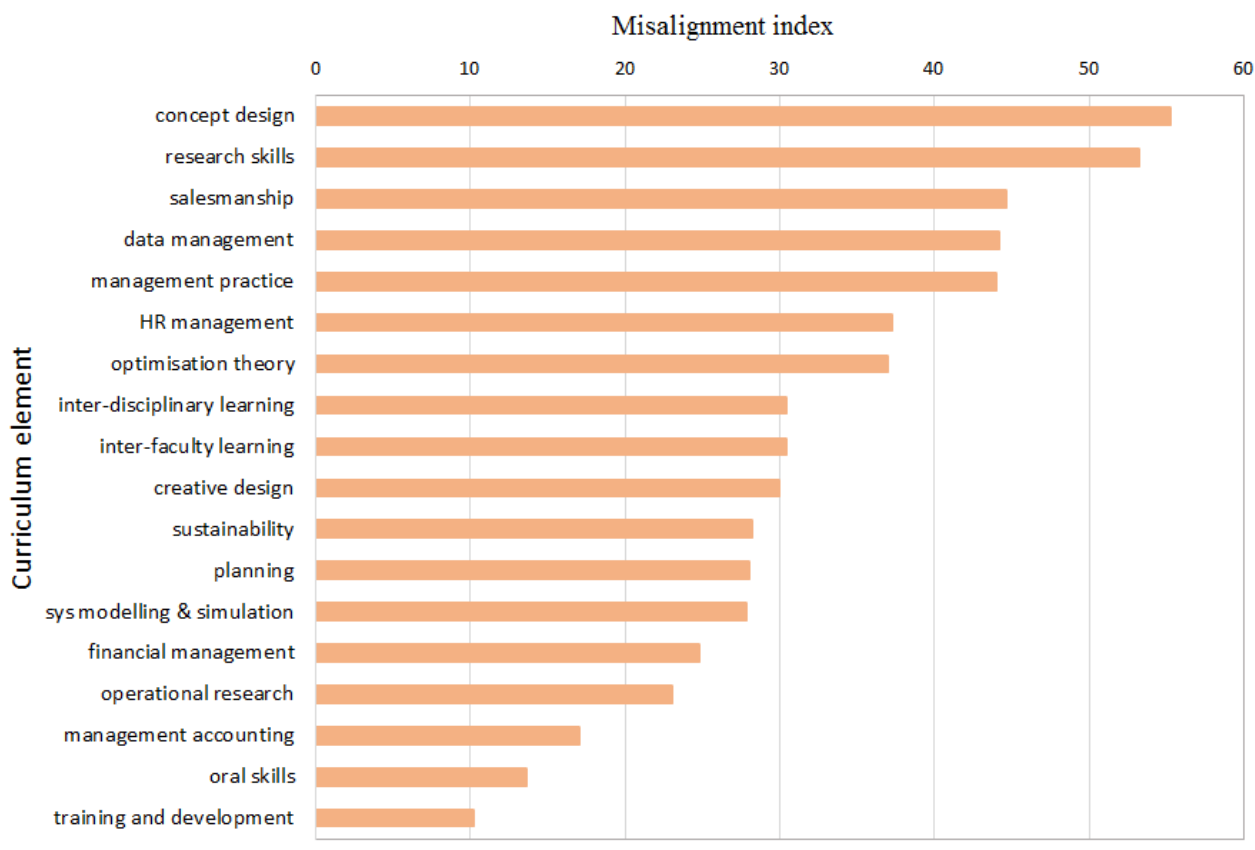

Figure 5: Elements with a positive mismatch 
A positive mismatch reflects poorly on the curriculum; and the purpose of the curriculum management system is to close this gap to achieve a close alignment of curriculum elements with industry.

\subsection{Implementing the alignment}

Figure 5 shows that, for example, the element of 'concept design' required a greater curriculum emphasis, and this emphasis was executed through curriculum manipulation at an atomic level rather than at a molecular level. To manipulate the curriculum to emphasise the 'concept design' element, the following was done:

Courses related to 'concept design' were identified. These courses were Mechanics, Mechanical Engineering Drawing, Mechanical Manufacturing Engineering, Electrical Engineering, Engineering Work Study, Facility Layout, and Materials Handling and Automation.

For the identified courses, the following aspects of the study programme were then biased more towards the 'concept design' element:

1. Student assignments

2. Case studies and problem examples

3. Laboratory/practical exercises

4. Examinations and tests

5. Course projects

Such was the expected outcome of the management system. Based on the industry input, the system computed recommendations for the appropriate management of the curriculum.

An evaluation determined the usefulness of the proposed curriculum management system compared with the conventional assessment system. From this evaluation, it was possible to measure the scope of the proposed curriculum management system.

\subsection{Evaluation}

The data collected and processed was sufficient to evaluate the proposed curriculum management system with atomic curriculum manipulation. This evaluation was made against the conventional assessment system (molecular-type manipulation) to determine its usefulness in aligning curriculum with industry need.

\subsubsection{Assessment system - output}

As part of the evaluation, reference was made to a typical conventional curriculum assessment system. An engineering assessment system review report [26] was analysed. This report was based on information gathered from alumni, current students, employers, staff, and engineering bodies. The output from this typical assessment system is of interest. In the case of Roger Williams University [26], it produced these recommendations:

1. Review engineering software

2. Review adequacy of laboratory equipment

3. Improve elective course selection list

4. More attention on written and oral communication skills

5. More attention on problem-solving and research

6. Create an engineering core concentration

7. Change ENVR course suffix to ENGR

8. Eliminate engineering minors and create specialisations

9. Eliminate the Water Pollution and Treatment course

10. Change course name from 'Robotics' to 'Mechatronics'

\subsubsection{Proposed management system - Output}

Figure 5 outlines the output from the proposed curriculum management system. This output directly aligned curriculum with the needs of the industry, and produced recommendations such as these:

More emphasis on the following elements (on a scale of 1-5):

1. Concept design (5)

2. Research skills (5)

3. Salesmanship (4)

4. Optimisation theory (3) 
5. Sustainability (2)

6. Oral skills (1)

These emphases were then implemented by biasing course projects, assignments, laboratory work, tests, and examinations accordingly, across all possible courses.

\subsection{Usefulness analysis}

The conventional assessment system is more generic (more academic), while the proposed curriculum management system is more industry-focused. The proposed curriculum management system speaks directly to the needs of the industry in terms of skills and knowledge. The conventional assessment system, for example, will recommend design projects to address more realistic (real-life) problems; but the management system will recommend the realistic problems that need to be addressed at a topic level. A graphical analysis of the impact of either system against industry needs is required to make a comprehensive evaluation. This analysis shows the degree to which both the conventional assessment system and the curriculum management system can align curriculum with the specific skills/knowledge needs of the industry. Figure 6 presents the analysis.

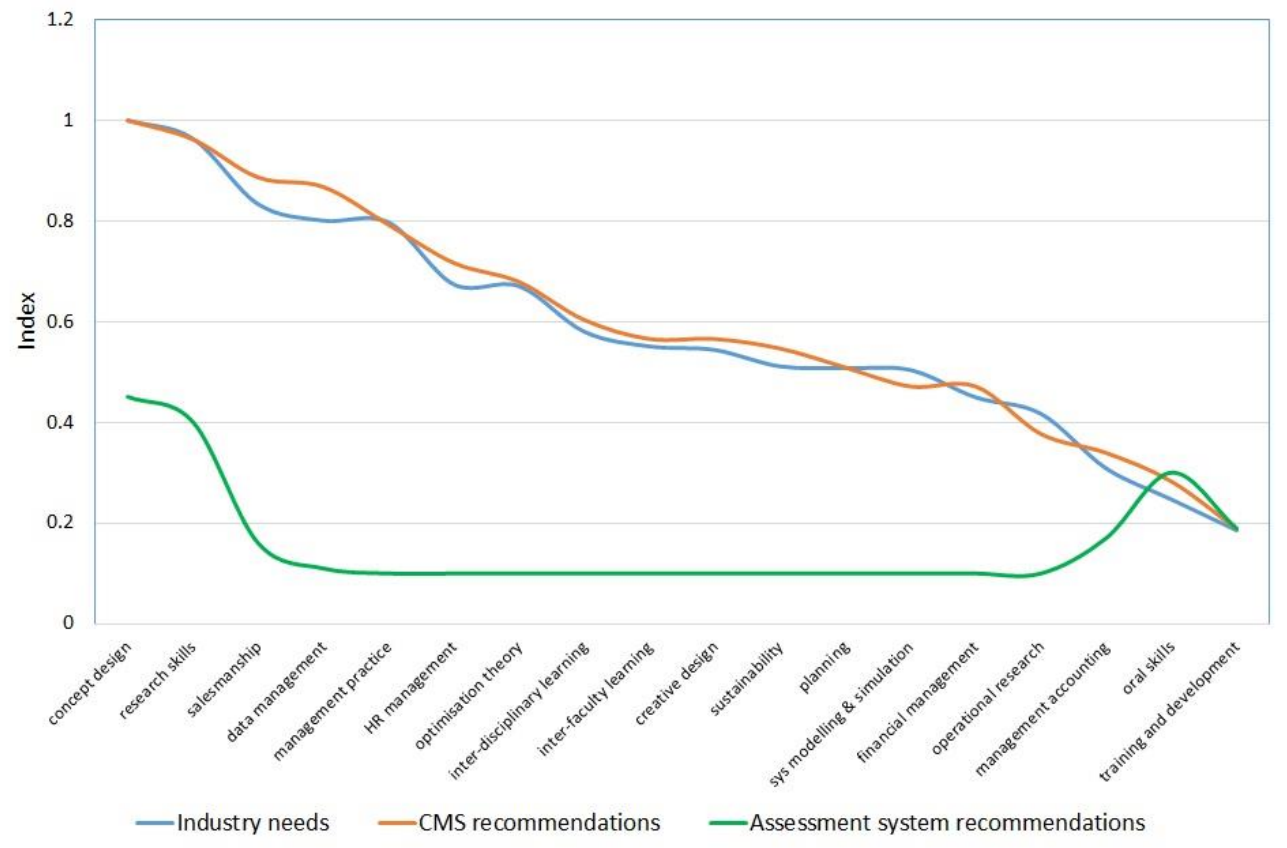

Figure 6: Industrial needs alignment potential

Figure 6 shows that, compared with the proposed system, the conventional assessment system is generally silent on the elementary requirements of the industry, although it sufficiently addresses academic-type requirements. The proposed curriculum management system, on the other hand, is industry-focused and flexible enough to adjust the curriculum specifically to meet industrial needs. To align the curriculum with industry needs, the proposed curriculum shows reasonable potential and effectiveness.

It must be noted, though, that while the proposed curriculum management system effectively serves the intended purpose of alignment, the system is silent on some of the tactical or operational factors that would otherwise be better addressed by the conventional assessment system. These include factors such as those addressing the adequacy of laboratory equipment, adjusting course titles, improving class schedules, and so on. This leaves room for further improvement.

\section{CONCLUSIONS AND RECOMMENDATIONS}

Curriculum is a key determinant of the graduate's skill level at the end of the study process. This skill level can best be measured by how well the graduate meets the requirements of industry. In this work, a curriculum management system is proposed to manage the curriculum of the Advanced Diploma in Industrial Engineering programme at the University of South Africa, based on information collected from the industry 
through on-line job/project advertisements. The proposed system uses atomic curriculum manipulation (secondary manipulation) by atomising each study course into key curriculum components, and then aligning these micro-elements with the needs of the industry, rather than manipulating whole courses. With the proposed atomic manipulation, curriculum alignment with industry needs adopts a more meticulous and holistic approach, while treating curriculum as the highly integrated ecosystem that it is. The results show that the proposed system is more strategic and intensive in managing curriculum and aligning it with the prevailing industrial needs than is the conventional method of curriculum assessment carried out by a select interfaculty sitting committee.

It is recommended that curriculum management be continually automated and executed, rather than periodically in an exercise by a sitting committee of faculty representatives. It is further recommended that the curriculum manipulation be executed at a secondary level by breaking down courses into subelements, rather than manipulating courses in their raw form.

\section{REFERENCES}

[1] Mialkki, H. \& Paatero, J.V. 2015. Curriculum planning in energy engineering education. Journal of Cleaner Production, 106, pp. 292-299.

[2] Rahman, N.A.A., Tan, K.L. \& Lim, C.K. 2017. Predictive analysis and data mining among the employment of fresh graduate students in HEI. AIP Conference Proceedings, 1891(1), 020007.

[3] Chuchalin, A. 2020. Evolution of the CDIO approach: BEng, MSc, and PhD level. European Journal of Engineering Education, 45(1), pp. 103-112.

[4] Monsalve, J., Uribe, A., Cardona-Gil, A., Osorio, M., Hincapie, C. \& Isaza C. Development of an automatic control system employing CDIO standards and competence-based learning. 15th International Conference on Information Technology Based Higher Education and Training (ITHET), Instanbu, 8 - 10 September 2016, pp. 1 - 7.

[5] Meyer, H., Strietholt, R. \& Epstein, D. 2018. Three models of global education quality and the emerging democratic deficit in global education governance. Routledge International Handbook of Teacher Quality and Policy. New York: Routledge.

[6] Kolmos, A., Hadgraft, R.G. \& Holgaard, J.E. 2016. Response strategies for curriculum change in engineering. International Journal of Technology and Design Education, 26(3), pp. 391-411.

[7] Baron, P. 2018. Hierarchical reflexive conversational teaching and learning as a vehicle for ethical engineering curriculum design. Constructivist Foundations, 13(3).

[8] Fomunyam, K.G. 2017. Decolonising the engineering curriculum in a South African university of technology. International Journal of Applied Engineering Research, 12(17), pp. 6797-6805.

[9] Nicholls, A. \& Nicholls, S.H. 2018. Developing a curriculum: A practical guide. London: Routledge.

[10] Perez-Foguet, A., Lazzarini, B., Gine, R., Velo, E., Boni, A., Sierra, M., Zolezzi, G. \& Trimingham, R. 2018. Promoting sustainable human development in engineering: Assessment of online courses within continuing professional development strategies. Journal of Cleaner Production, 172, pp. 4286-4302.

[11] Chau, K. 2007. Incorporation of sustainability concepts into a civil engineering curriculum. Journal of Professional Issues in Engineering Education and Practice, 133(3), pp. 188-191.

[12] Azemi, A. 2018. Promoting innovation and entrepreneurship as part of an engineering curriculum. IEEE Frontiers in Education Conference (FIE), San Jose, 3 - 6 )ctober 2018, pp. 1-5.

[13] Alarifi, A., Zarour, M., Alomar, N., Alshaikh, Z. \& Alsaleh, M. 2016. SECDEP: Software engineering curricula development and evaluation process using SWEBOK. Information and Software Technology, 74, pp. 114-126.

[14] Elhoseny, M., Metawa, N. \& Hassanien, A.E. 2016. An automated information system to ensure quality in higher education institutions. 2016 12th International Computer Engineering Conference (ICENCO), Cairo, 28 - 29 December 2016, pp. 196-201.

[15] Varfolomeyev, A., Pitukhin, E. \& Nasadkin, M. 2015. Curriculum management information system. 8th International Conference of Education, Research and Innovation, November 2015, Seville, Spain.

[16] Garousi, V., Giray, G., Tuzun, E., Catal, C. \& Felderer, M. 2019. Closing the gap between software engineering education and industrial needs. IEEE Software, 37(2), pp. 68-77.

[17] Baker, J. 2018. 2018's software engineering talent shortage - It's quality, not just quantity. [Online] Available from https://hackernoon.com/2018s-software-engineering-talent-shortage-its-quality-not-just-quantity6bdfa366b899. Accessed: 15 July 2020.

[18] Tilson-Scoble, V.J. 2018. The misalignment between the expectations of fashion students, fashion tertiary educators, and the fashion industry. Thesis, University of Otago.

[19] Zimmer, W.K. \& Keiper, P. 2020. Redesigning curriculum at the higher education level: Challenges and successes within a sport management program. Educational Action Research. DOI: 10.1080/09650792.2020.1727348

[20] Akdur, D. 2019. The design of a survey on bridging the gap between software industry expectations and academia. 8th Mediterranean Conference on Embedded Computing (MECO), Budva, 10 - 14 June 2019, pp. 1-5.

[21] Zandin, M. 2004. Industrial engineering handbook, $5^{\text {th }}$ ed. New York: McGraw-Hill.

[22] Sage, A.P. \& Rouse, W.B. 2014. Handbook of systems engineering and management, $2^{\text {nd }}$ ed. Hoboken, NJ: John Wiley \& Sons. 
[23] Engineering Council of South Africa. 2019. Discipline-specific training guide for candidate engineering technologist in industrial engineering. [Online] Available from https://www.ecsa.co.za/ECSADocuments/Shared\%20Documents/R-05-IND-PT\%20Disciplinespecific\%20Training\%20Guideline\%20for\%20Candidate\%20Technologists\%20in\%20Industrial\%20Engineering.pdf. Accessed: 1 July 2020

[24] Engineering Council of South Africa. 2019. Discipline-specific training guide for candidate engineering technician in industrial engineering. [Online] Available from https://www.ecsa.co.za/ECSADocuments/Shared\%20Documents/R-05-ELE-PN\%20Discipclinespecific\%20Training\%20Guideline\%20for\%20Candidate\%20Engineering\%20Technician\%20in\%20Electrical\%20Engineer ing.pdf. Accessed: 1 July 2020.

[25] Litecky, C., Aken, A., Ahmad, A. \& Nelson, H.J. 2010. Mining for computing jobs. IEEE Software, 27, pp. 78-85.

[26] Roger Williams University. 2016. Assessment report for the engineering program. [Online] Available from https://www.rwu.edu/sites/default/files/downloads/seccm/seccm_engineering_assessment_report_ay1011.pdf. Accessed: 10 July 2020. 